\title{
DE LA REALIDAD AL MAPA: ¿UN PROCESO CREATIVO MÁS ALLÁ DE LA TÉCNICA?
}

\author{
José Sancho Comíns \\ Universidad de Alcalá \\ jose.sancho@uah.es
}

ORCID iD: https://orcid.org/0000-0002-1777-8498

Recibido: 21/12/2017; Aceptado: 10/12/2018.

Cómo citar este artículo/Citation: Sancho Comíns, J. (2019), De la realidad al mapa: ¿un proceso creativo más allá de la técnica?. Estudios Geográficos, 80 (286), e002. https://doi.org/10.3989/estgeogr.201922.002

RESUMEN: El mapa, como es bien sabido, posee una gran capacidad de transmitir información temática de un determinado territorio. Lo hace mediante un lenguaje visual muy poderoso cuyo uso implica procesos científicos, técnicos y artísticos muy exigentes en la fase de su elaboración y otros de tipo receptivo por parte de aquellos que a él se acercan. El mapa, por tanto, no es un mero producto técnico, sino que concita una actividad intelectual más amplia que podría equipararse a un verdadero proceso creativo. En este trabajo se sintetiza, en primer lugar, la experiencia del autor como "geógrafo que hace mapas y enseña a hacer mapas"; en segundo lugar, se dan razones que sustentan la idea de que el mapa es algo más que el resultado de utilizar correctamente los recursos técnicos adecuados; y, por último, se perfila un marco en el que, a su modo, el trabajo cartográfico participa también de los valores fundamentales dibujados en el horizonte de este nuevo milenio, en concreto, por parte de algún creador literario.

PALABRAS CLAVE: Cartografía Temática; Componentes del Mapa; Metodología del Trabajo Cartográfico; Valores y Creatividad Cartográfica.

\section{FROM REALITY TO A MAP: A CREATIVE PROCESS BEYOND TECHNIQUE?}

ABSTRACT: The map, as it is well known, has a great capacity to provide thematic information about a territory. It does it using a very powerful visual language, which implies demanding scientific, technical and artistic processes during the creation process, as well as receptive processes by the observer. For this reason, the map is not only a technical product, but it also implies a broad intellectual activity that could be comparable to any other creative process. This work synthesises the author's experience as a "geographer who makes maps and teaches how to make maps". It also provides reasons to sustain the idea that a map is more than the result of correctly using technical resources, and that maps are also part of the new millennium values and challenges pointed out by other creators in the literary field.

KEY WORDS: Thematic Cartography; Map Components; Methodology of Cartographic Work; Cartographic Values and Creativity. 


\section{INTRODUCCIÓN}

Resulta una obviedad recordar que la comunidad humana a lo largo de la historia siempre trató de compartir conocimientos, vivencias, tradiciones, creencias y todo lo que iba acumulando en ese monumental bagaje cultural y científico que se ha ido transmitiendo de generación en generación. Y siempre lo hizo por medio del lenguaje apropiado para cada caso; unas veces fue la expresión oral o escrita; otras la imagen y no pocas el simbolismo de fiestas, costumbres y tradiciones, entre otros modos.

Como es bien sabido, esa necesidad de compartir no se explica solo por las posibilidades que el hombre tiene como ser capaz de expresarse inteligentemente, sino también por su condición radical de ser social. Así pues, la expresividad humana no es hija tan solo de una exigencia interior y sus correspondientes posibilidades de manifestar un contenido determinado, sino que encuentra su verdadero sentido cuando alguien acoge lo expresado, lo entiende y lo hace suyo o bien lo rechaza.

Es, por tanto, el hecho sustancial de la comunidad humana como comunidad "relacionada" el que crea y sostiene el lenguaje como medio de comunicación. El mapa aparece en este marco como recurso capaz de transmitir información territorial; unas veces cuantitativa, otras cualitativa; objetiva y tangible o bien intangible; también lo hace con contenidos estáticos o dinámicos, o bien visualiza los resultados de procesos analíticos, sintéticos o tipológicos mediante los que se quiere caracterizar la realidad geográfica.

Cuando la Asociación Cartográfica Internacional, en 1966, definió la cartografía, lo hizo apelando a dos grupos de elementos fundamentales que la sustentan: Estudia, por un lado, todo lo relativo a la producción cartográfica (Conjunto de procesos científicos, técnicos y artísticos) y, por otro, al uso del mapa (Conjunto de procesos receptivos que se activan en quien utiliza un mapa). Se trata, por tanto, de generar un recurso visual que a modo de puente haga posible el flujo de informaciones entre quienes las han generado y aquellos interesados en conocerlas. El mapa solo adquiere tal condición cuando productor y usuario se encuentran en él y, de manera inteligente, son capaces de hacerse entender por parte de aquel y acoger satisfactoriamente el conocimiento ofrecido por parte del segundo. La cartografía, como ciencia, tiene, por tanto, una doble tarea que cumplir; por una parte, estudia los procesos productivos que maneja y controla el ejecutor y, por otra, indaga cómo impulsar la adquisición de las destrezas necesarias para un uso concreto y provechoso del mapa.
Los procesos productivos entrañan una cierta complejidad pues solicitan la atención, simultáneamente, de tres facetas. Por un lado, la elaboración de un mapa es enormemente exigente desde el punto de vista científico. Se trata de transformar un dato en información; ello comporta la aplicación de metodologías propias de la ciencia: veracidad de los datos de partida, planteamiento de hipótesis, rigor en el tratamiento de aquellos, acierto en la expresión de resultados y probada validez del producto obtenido, en este caso el mapa.

En segundo lugar, no es menor la complejidad del proceso técnico exigible: por un lado, creación de un soporte métrico que posicione los fenómenos territoriales con precisión matemática y exacta referenciación a coordenadas de longitud y latitud; por otro, todo lo referente al manejo del lenguaje cartográfico. Este posee una determinada sintaxis y, por tanto, unas reglas que regulan su uso; se requiere el dominio de estas y la suficiente experiencia para aplicarlas con acierto. No es desdeñable, por otra parte, la importancia del proceso de preparación técnica de los materiales de edición; en él se contempla, en definitiva, la puesta en escena del mapa. Al llevar a cabo esta concreción puede ocurrir que desmerezca el trabajo realizado anteriormente, caso de no cuidar con esmero las "últimas piedras" en la construcción del mapa, o bien se ennoblezca el mismo de modo significativo si la ejecución se ha llevado a cabo con acierto.

Por último, la Asociación Cartográfica Internacional alude a la concurrencia de un proceso artístico en la elaboración de un mapa. Entiende la $\mathrm{ACl}$ que el mapa es una imagen y como tal debe reunir ciertos valores estéticos que hagan de ella un recurso atractivo, sugerente y fácil de memorizar en sus trazos generales. No basta, por tanto, con verter información cierta en un soporte métrico adecuado, es necesario que la imagen cartográfica sea agradable de ver. Despertar en el usuario el gusto por contemplarla se convierte en condición necesaria; su aceptación o rechazo, incluso a nivel inconsciente, por parte del observador puede condicionar o bien tan solo un aprovechamiento en frío desde el punto de vista científico, o bien llevar a cabo esto último con mayor agrado si la imagen cartográfica reúne cualidades para ello.

La ejecución de un mapa, y por extensión la de un atlas temático o geográfico, tiene, por tanto, su complejidad. Representar o recrear la realidad en una imagen cartográfica o desplegarla a lo largo y ancho de un atlas, no es fácil. Se necesita conocer bien aquélla y aplicar rigurosamente una metodología exigente. 
Mas el proceso no puede calificarse de "meramente técnico"; sería un planteamiento equivocado entender la elaboración de un mapa como la transposición automática de una información territorial que caracteriza una determinada realidad a otra realidad nueva que es el mapa. Sería igualmente una torpeza, o más bien un fraude, el empeño de crear imágenes bellas sin el debido sustento científico y técnico.

En este trabajo quiero hacer hincapié precisamente en la importancia del proceso creativo que va más allá de la técnica y se imbrica con cada paso que damos en la ejecución del mapa. Un proceso, por tanto, transversal que impregna todo lo que ocurre desde el mismo momento en que se inicia la elaboración del mapa hasta la terminación del mismo. El mapa, insisto, no es un producto de cariz exclusivamente científico y técnico, su ejecución exige también el concurso de metodologías propias de otros procesos creativos. El empuje de las nuevas Tecnologías de la Información Geográfica (TIG), las posibilidades absolutamente impensables hace una décadas de obtener información territorial a partir de fuentes satelitales y sensores aerotransportados, la existencia de riquísimos y actualizados repertorios estadísticos, y, en suma, la formidable acumulación de conocimiento científico en medios de fácil acceso, no desterrará nunca la necesidad de tener en cuenta los pasos propios a lo que en este trabajo denominamos "creación cartográfica"; esta pertenece al sustrato esencial, irrenunciable, en el que lo nuevo debe ser insertado.

No quiero, en manera alguna, equiparar en igualdad de condiciones, por ejemplo, los procesos creativos en la "expresión cartográfica" con los propios a la "creación artística"; tan solo deseo señalar que como "geógrafo que hace mapas" me ha llamado la atención la experiencia que artistas y literatos han explicitado tantas veces sobre su propio proceso creador. ¿Será, acaso, porque existe un tibio parentesco entre la creación artística y el trabajo del cartógrafo? Sería pretencioso por mi parte tratar de demostrar que sea así; por eso, formulo mi inquietud en forma de pregunta y no de hipótesis de trabajo. Humildemente me he acercado al quehacer de reconocidos creadores para ver tan solo si en nuestro trabajo resuena un eco lejano de la experiencia de estos.

En lo que sigue expondré brevemente, en primer lugar, los conceptos y los materiales que utilizamos en un proceso de "elaboración de mapas temáticos"; en un segundo apartado, centraré mi atención en desvelar algunos síntomas que pudieran acaso otorgar a nuestro trabajo, siquiera metafóricamente, el calificativo de "creador"; por último, señalaré determinados valores que, descritos previamente por un escritor como tales, pueden ser también para nosotros válidos en nuestro quehacer. No tiene más objetivo esta reflexión que transmitir mi experiencia acumulada a lo largo de más de treinta años como responsable de la ejecución de una docena de atlas temáticos junto a lo que me han hecho pensar algunos escritores y artistas cuando han descrito su propio proceso creativo. Lo he hecho habitualmente en las clases ante mis alumnos; ahora me atrevo ante quien se acerque a estas páginas.

\section{LOS COMPONENTES CONCEPTUALES Y MATERIALES DEL MAPA}

Sin necesidad de apelar a ningún posicionamiento filosófico, a mi parecer, está claro que el mapa está hecho de materia y espíritu; con una expresión más rudimentaria suelo decir a mis alumnos que el mapa es de "carne y hueso". Vemos formas, colores, texturas y dimensiones, pero no solo eso, percibimos también el andamiaje que sostiene lo visible; esas ideas madre que indefectiblemente están en todo mapa y que solemos denominar componentes conceptuales: información, formación y atracción.

Antes de adentrarnos en el proceso creativo del mapa propiamente dicho, dedicaré este apartado a recordar ese doble componente que lo sustenta; por un lado, las ideas madre a las que me acabo de referir y, por otro, los artefactos que son utilizados en su construcción. Dicho de otra manera, consideraré primeramente ese armazón o cimiento, sustancial al mapa, sin el cual sería imposible, después, construir materialmente el mismo.

\subsection{La sustancia del mapa}

Todo mapa obedece a un qué, a un para qué, a un para quién y a un cómo. El "qué" bien sabemos que se sustancia en la información territorial contenida en él, bien de orden básico (toponimia, hidrografía, límites administrativos, topografía...), bien de cariz temático (geología, clima, población, comercio...). Esta información debe ser clara y no crear en el usuario incertidumbre alguna, sino más bien facilitar una lectura inteligente. El "para qué" alude al objetivo del mapa; unas veces será generalista, cultural o meramente informativo, otras científico/académico y no pocas prospectivo; este aspecto debe estar claro desde el comienzo, guiando así la ejecución práctica del mapa para que alcance el máximo grado de eficacia. El "para quién" está muy ligado a lo que acabamos de decir: el público al que se dirige el mapa, unas veces 
amplio y general, y otras, minoritario y específico. De ese potencial usuario debe ser conocida su destreza en la lectura cartográfica, que condiciona, a su vez, determinadas decisiones en orden al empleo de la simbología (de lo figurativo a lo abstracto), así como al tratamiento de la información (de lo analítico a lo sintético); con ello se busca la mayor eficiencia posible. Por último, el "cómo" resulta clave en el proceso generador del mapa; respeto a la sintaxis cartográfica y creatividad en el empleo del lenguaje visual se aúnan indisolublemente; lo primero para mantener la racionalidad y fácil entendimiento del mapa, lo segundo para diseñar, a partir de la potencialidad propia de este tipo de lenguaje y el ingenio humano, nuevas formas de expresión que doten el mapa de la mejor condición posible.

Así pues, un triple componente sostiene a la imagen cartográfica: informativo, formativo y estético. Se trata de ofrecer una imagen con sustancia: el mapa nos dice algo siempre; el mapa tiene en cuenta al potencial usuario con su capacidad de lectura cartográfica, contribuyendo, a su vez, a mejorar su destreza en la percepción de la información cartográfica por la excelencia del mapa que ahora es objeto de uso; el mapa, por último, se presenta con ciertos valores estéticos que favorecen decisivamente el gozo en la contemplación del mismo. Estos tres componentes guían a cada momento al cartógrafo en el proceso de ejecución del mapa; son los bastidores que sostienen, en suma, su trabajo. Solo así se podrá cumplir con éxito aquel triple objetivo de hacer posible la inteligencia de la información, guardar en memoria lo esencial de ella y disfrutar al mismo tiempo.

FIGURA 1

LA SUSTANCIA DEL MAPA

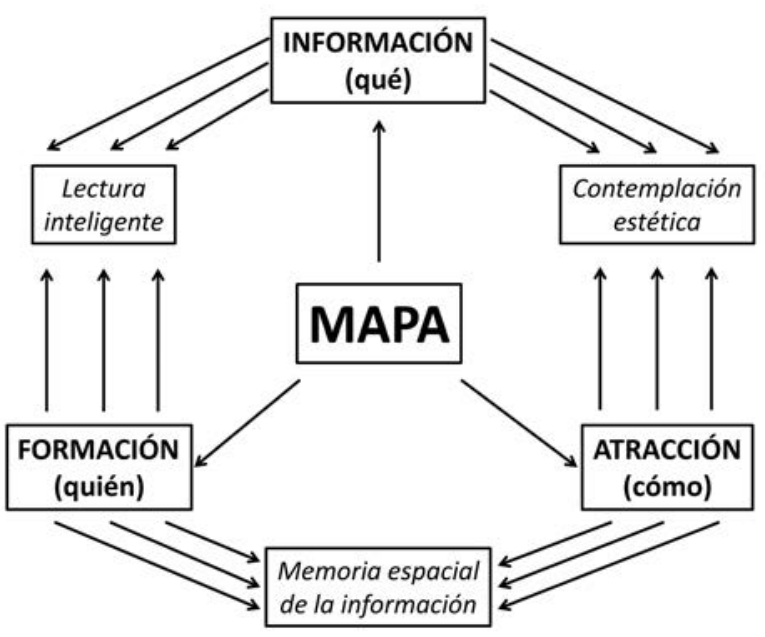

\subsection{La materialización del mapa}

Lo que sin ánimo despectivo hemos llamado "artefactos" del mapa solo entrarán en escena cuando el andamiaje estructural al que nos acabamos de referir esté firme, bien asentado. Consciente el cartógrafo de sus objetivos, conocedor del usuario potencial y sabedor de la necesidad de dotar a la imagen cartográfica de un cierto atractivo, se pone en marcha, reúne piezas y le pone "carne" a la "osamenta". Son los componentes materiales los que, con las limitaciones de cada uno, toman entonces protagonismo y tratan de ayudar al cartógrafo en el desafío que tiene planteado: construir una imagen que sin ser la misma realidad, diga de esta lo esencial del contenido temático objeto de representación.

Se decide la escala, es decir, la representación proporcional del territorio como recipiente métrico que acoge el contenido temático; también la proyección que ha hecho posible representar en una superficie plana la que es curva en la realidad; se incorpora la información básica conveniente; se añade, después, la carga temática sirviéndose para ello de la simbología adecuada; por último, se completa la composición con otros detalles que no dejan de ser importantes: marco que recuadre el mapa, escala gráfica y, si fuera conveniente, numérica, leyenda, título del mapa, fuente de la información básica y temática, indicación de la posición geográfica del territorio tratado mediante la señalización en el marco de la longitud y latitud, etc.

Ambos componentes, los conceptos madre y los artefactos materiales, quedan al fin imbricados en una imagen que toma vida propia. Es capaz de hablar a su manera; tiene capacidad de responder a determinadas preguntas y no son menos elocuentes las cuestiones que nos plantea, configurándose alguna de ellas como auténticas hipótesis para una indagación futura. Si el mapa queda inserto en un discurso cartográfico junto a otros mapas, la composición, que recibe entonces el nombre de atlas, puede llegar a ser la expresión más fiel de las características geográficas de un territorio como lo son las catedrales de la fe de un pueblo.

No son, por tanto, los mapas productos automáticos que hoy más que nunca salen sin más de un complejo tecnológico con grandes prestaciones. Si así fuera, podríamos dar por muerta la cartografía y desaparecido el oficio de "hacer mapas". Siendo imprescindible el dominio técnico de las herramientas de producción cartográfica y enormemente beneficiosos los avances producidos en las últimas décadas, no puede confiar- 
se solo al complejo tecnológico la responsabilidad de la ejecución cartográfica, ni tampoco atribuir a este el mérito de los excelentes mapas que hoy están al alcance de todos nosotros. El mapa es y seguirá siendo una imagen que ha requerido un proceso creativo más allá de la técnica. Eso es lo que a continuación trataré con algo más de detenimiento.

\section{De la Representación a la Recreación de la ReA- LIDAD GEOGRÁFICA}

La observación detenida de la realidad geográfica, -pongamos por caso un valle con asentamientos humanos, áreas industriales, comerciales y plataformas logísticas, vías de comunicación de distintos tipos, franjas de cultivo en las laderas bajas de escasa pendiente y espacios forestales en la parte alta de las sierras que lo delimitan- nos proporciona información localizada sobre los grandes tipos de cubierta biofísica que ocupan su epidermis, unas veces llana, otras ondulada y no pocas arrugada a la vez que gana altitud o la pierde. El buen observador se queda con una imagen que nos habla de diversidad, complejidad y vitalidad; al mismo tiempo, todo aquel entramado respira también un cierto orden alusivo al concierto que reina entre sus propias posibilidades de aprovechamiento y las decisiones que la comunidad humana ha tomado en relación a su óptimo uso.

La dificultad comienza para el cartógrafo cuando, consciente de lo inasible que es el entorno, quiere representar todo o parte de aquel en un mapa. Si el territorio objeto de estudio y representación cartográfica es más amplio hasta abarcar una comarca, región, país o continente, y hasta el planeta Tierra en su conjunto, el desafío crece exponencialmente. El primer paso consiste en la formación de una idea que refleje la mayor cercanía posible a la realidad que se quiere representar; es decir, sea verdadera, a sabiendas que la realidad nunca podrá ser encerrada en ella, ni la identificación, por tanto, será plena y total. El cartógrafo se moviliza, busca información complementaria, ausculta aquella realidad territorial lo más que puede y aplica, al fin, la metodología adecuada para el tratamiento de los datos y su visualización gráfica en un mapa. Este se convierte, entonces, en el recurso puente para un potencial usuario que desea "conocer" un territorio. Se desencadena, en ese momento, el proceso inverso de lectura cartográfica, aprehensión del contenido de mapa, formación de conocimiento científico o adquisición de una simple información y vuelta a la realidad desde la idea generada.

FIGURA 2

LA MATERIALIDAD DEL MAPA

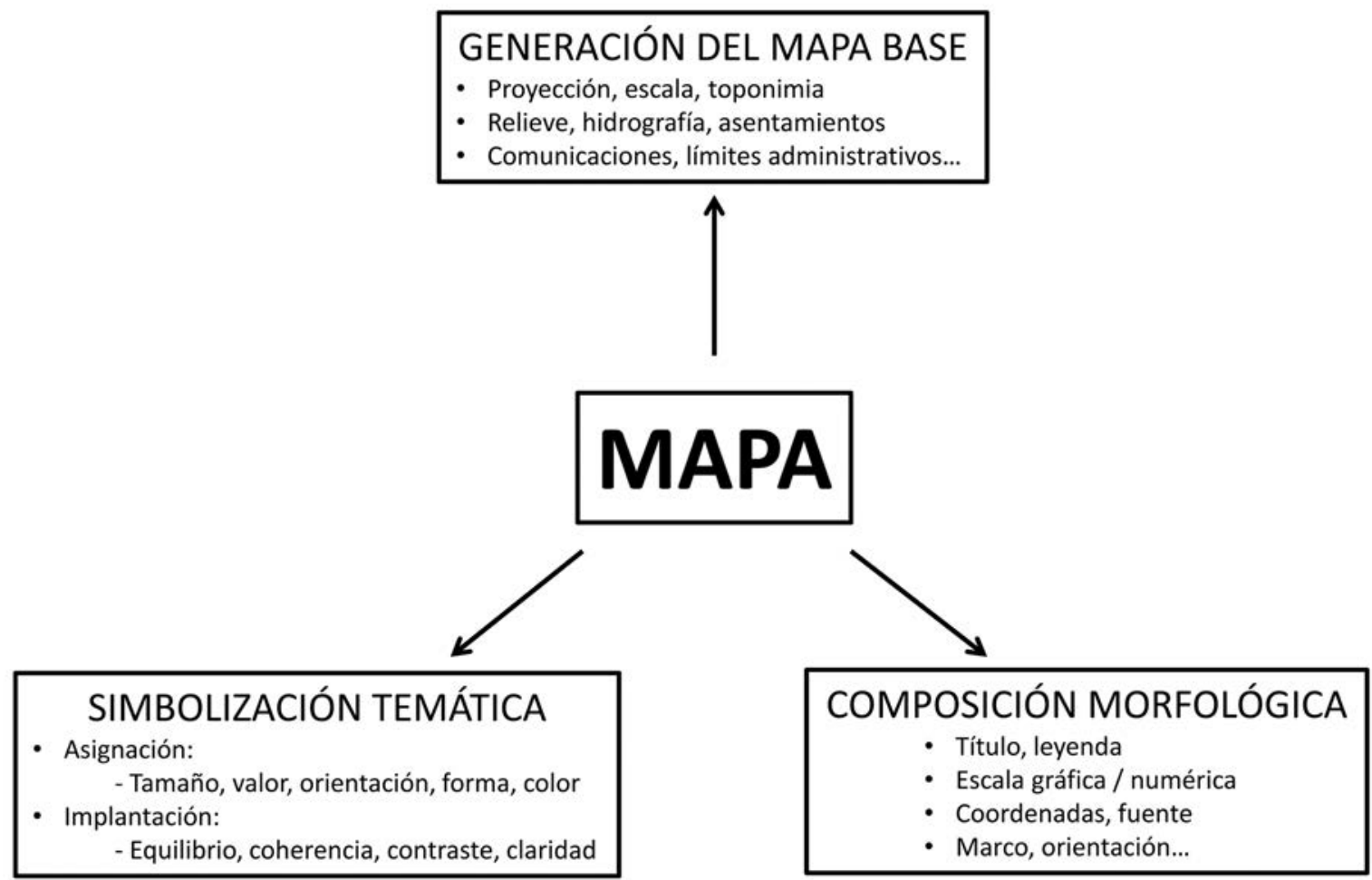




\section{REALIDAD GEOGRÁFICA}

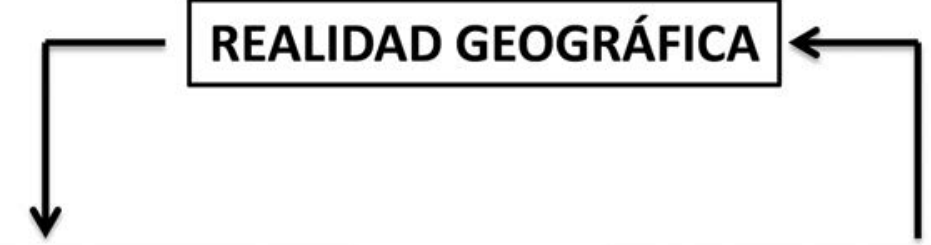

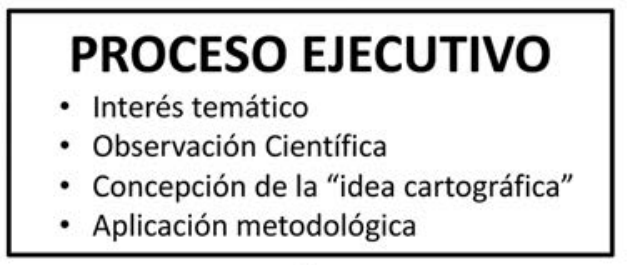

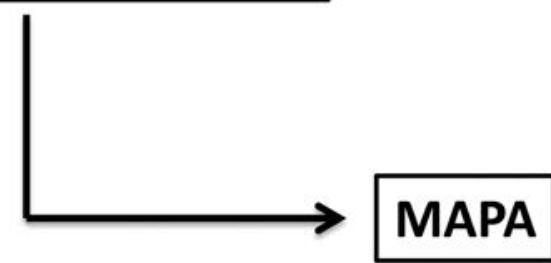

- Formación del "Conocimiento Científico"

- Aprehensión del contenido

- Lectura cartográfica

- Interés Temático

\section{PROCESO RECEPTIVO}

Únase a ello que la intención de quien ejecuta el mapa va siempre más allá de lo estrictamente material; busca reflejar lo que realmente anima al territorio y a su gente; es decir, acercarse lo más posible a su "alma". No resulta extraña esa misma preocupación a muchos creadores como, por ejemplo, a Leo Perutz cuando describe al pintor Brabanzio que, ante la imposibilidad de satisfacer la petición del judío Mordejai Meisl, empeñado en que le hiciera un retrato a su esposa Esther, ya fallecida, le contestó: "Cuando pinto el retrato de una persona no me basta con ver su cara, que es mudable y que hoy muestra un aspecto y mañana otro. Le hago preguntas y no cejo hasta que he logrado adentrarme en su alma. Porque solo así soy capaz de hacer un buen retrato" (Perutz, 2016). Algo similar dice Marina Tsvietáieva de su buen amigo V.L. Mchedelov, autor teatral, al describirlo como "hombre de lo visible con pasión por lo invisible" (Tsvietáieva, 2015).

Es tal el esfuerzo de generalización y abstracción y son tales las dificultades y limitaciones de expresión por parte del lenguaje cartográfico que el producto elaborado -el mapa- es una nueva realidad, aunque bien enraizada en la geográfica. Ese nuevo ser -la imagen cartográfica- toma vida propia y a modo de un organismo se presta al diálogo con los usuarios que a él se acercan. En suma, el cartógrafo más que una representación aséptica de la realidad, cosa prácticamente imposible, aunque se tenga como deseable, hace una recreación de la misma en un nuevo ente, en este caso visual. El camino queda abierto para que el usuario revierta el proceso: del mapa a la idea y de esta a la realidad. No se nos escapa la dificultad del proceso.

Quisiera detenerme a continuación en dos aspectos que también he podido ver en el proceso de creación artística o literaria. En primer lugar, el inevitable esfuerzo que solicita la ejecución de un empeño de este estilo; y, en segundo lugar, la necesaria disciplina metodológica, oculta casi siempre, que aplica, en nuestro caso, el "hacedor de mapas" como también lo hace, por ejemplo, el creador literario.

\subsection{El esfuerzo, condición inevitable}

La creación de un mapa, como la de cualquier obra bien hecha, va necesariamente ligada al esfuerzo. No es fácil elegir con acierto aquel aspecto del territorio que pueda representar a este con fidelidad y especificidad en un mapa; los procesos analíticos requieren una atenta observación pues son muchas las facetas que se congregan ante el estudioso y la selección se hace costosa. Tampoco es fácil escoger el tratamiento más idóneo para preparar esos datos de tal manera que el resultado de su manipulación no altere la verdad originaria y la imagen cartográfica siga siendo el mejor reflejo de aquella. Por último, la simbolización es un paso arduo cuando las opciones son muchas; el cartógrafo maneja un lenguaje y este posee una poten- 
cialidad enorme que exige destreza en su manejo, esfuerzo por encontrar la mejor forma de expresión y un punto de genialidad para crear composiciones atractivas sin menoscabar el objetivo esencial del mapa, cual es la transmisión de una información territorial.

Así pues, estamos ante un trabajo que requiere una atención intensa, un talento bien armado y, en suma, un esfuerzo nada desdeñable. No pueden resultarnos extrañas las palabras que Rainer María Rilke dirigió a su buen amigo el escultor Auguste Rodin: "Es menester trabajar, nada más que trabajar. Y hay que tener paciencia" (Rilke, 2004). En la misma línea se han manifestado conocidos escritores como Mario Vargas Llosa al decir "No tengo talento natural, me cuesta trabajo escribir" (Salinas, 2015), o bien Antonio Muñoz Molina cuando confiesa "Escribir es como respirar con dificultad" (Salinas, 2015). Está claro, pues, que el esfuerzo acompaña a todo aquel que se adentra en proyectos bien fueran científicos o puramente creativos.

Otra cosa es que ese esfuerzo se visualice. No es deseable, por ejemplo, que un usuario potencial de un atlas geográfico perciba la pesada labor desarrollada en su ejecución; no sería un mérito para ese mismo atlas que el juicio positivo del mismo se basara exclusivamente en el reconocimiento del esfuerzo que los científicos han realizado y lo costosa que ha sido la ejecución técnica. Lo ideal es difuminar el esfuerzo hasta hacerlo desaparecer de tal manera que no llegue a percibirse. "El esfuerzo no debe notarse, si el lector lo percibe, molesta" (citado por Delclaux, 1996) señalaba Jorge Luís Borges.
No obstante, tampoco es bueno que la obra bien hecha quede como producto edulcorado que ha sido creada sin contratiempos ni dificultades y hasta sin un desgaste personal bien notado por quien la creó. Un atlas temático o geográfico con toda seguridad ha vivido contratiempos en su elaboración; no solo los propios a la ejecución científica y técnica, sino también a la generación de la estructura organizativa más idónea, al aprovechamiento pleno de las sinergias colaborativas y, no pocas veces, a las limitaciones de orden financiero que pueden malograr un proyecto de esta envergadura.

Por eso, atribuyo también una cierta bondad a dejar entrever ese panel de esfuerzos y dificultades que se pueden haber vivido a lo largo del trabajo desarrollado en llevar a cabo un empeño tan complejo como la realización de un atlas. Sería una lástima no transmitir el aprendizaje obtenido por parte de los responsables científicos y técnicos en afrontar y solucionar las dificultades. Creo muy oportuno traer aquí la reflexión hecha por Henry Matisse en sus "Cartas a grandes artistas" en la que aborda magistralmente la doble intención que él siempre tuvo en su creación artística: "Siempre he tratado de ocultar mis esfuerzos deseando que mis obras tuvieran la ligereza y la alegría de la primavera, que no hace imaginar a nadie el trabajo que ha costado. Así temo que los jóvenes, al no ver en mi trabajo si no la aparente facilidad y el descuido en el dibujo, lo utilicen como pretexto para dispensarse de algunos esfuerzos que creo necesarios" (citado por Delclaux, 1996).

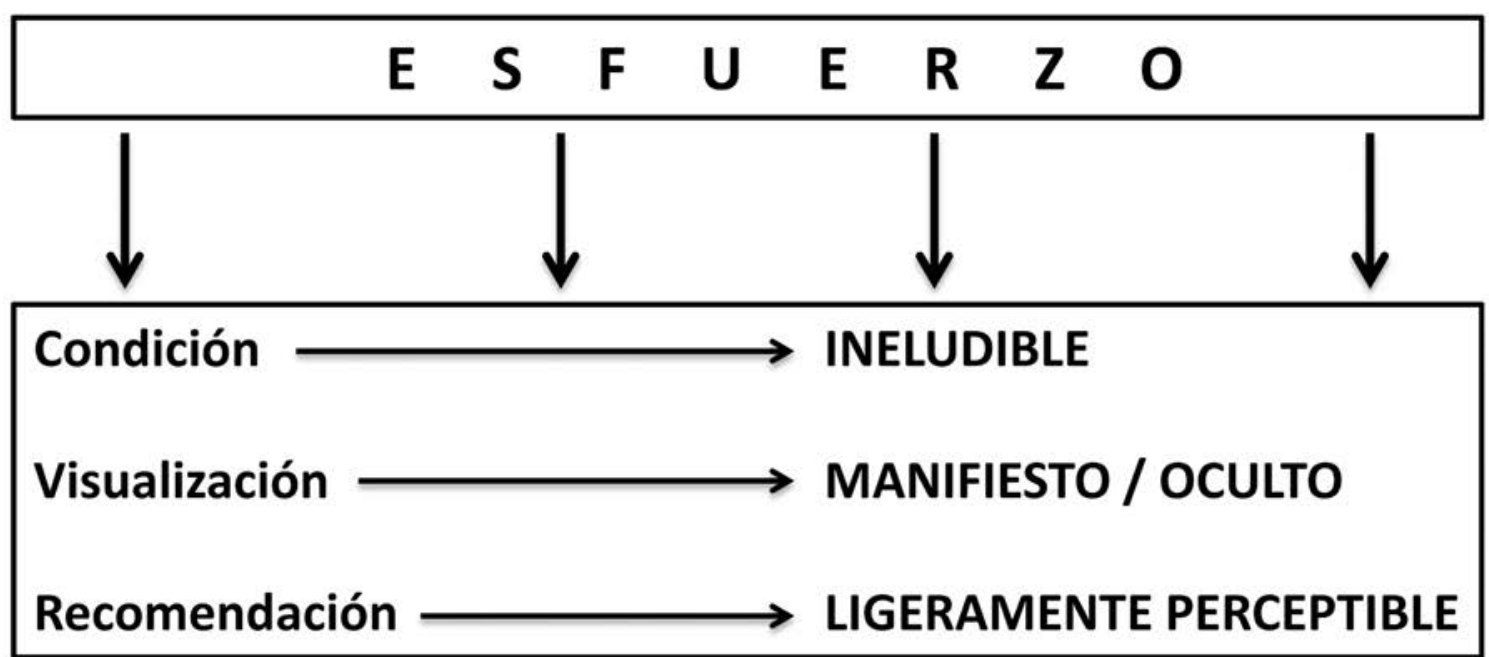




\subsection{Algo más que rigor metodológico}

Son muchos los estudiosos que se han preocupado de diseñar los caminos que la ciencia positiva o la especulación filosófica deben recorrer en busca de la verdad. Corrientes filosóficas de distinto cariz y cultivadores de la ciencia positiva han formulado los pasos a dar en la investigación para que esta aporte resultados rigurosos, válidos para el progreso del conocimiento y casi siempre aplicables para la mejora de las condiciones de vida de la comunidad humana y su entorno natural. No es este el lugar apropiado para sintetizar todo el bagaje acumulado a lo largo de la historia a este respecto. Doy por supuesto que nuestro trabajo se enmarca en los postulados estrictos del rigor metodológico exigible; lo que a continuación relato, sin el ánimo de ser exhaustivo, son rasgos que me han llamado la atención en las confesiones que algunos creadores hacen sobre el proceso de su trabajo y que nos pueden ayudar a profundizar en determinados aspectos de nuestro propio quehacer.

\subsubsection{Cercanía a otros procesos creadores}

Puede resultar frívolo decir que, de entrada, es muy conveniente reunir dos condiciones en los ejecutores de un proyecto cartográfico como un atlas: salud y buen humor. No lo es tanto si quien lo asevera es Álvaro Pombo cuando dice: "Una condición indispensable para escribir es estar bien de salud y estar de buen humor" (Salinas, 2015). Coincidimos en esta apreciación y la experiencia no hace sino ratificar lo dicho; las dificultades necesitan temple para afrontarlas, serenidad en la toma de decisiones para superarlas y una prudente administración de las respuestas que no por rápidas Ilegan a ser eficaces. El profesor José Antonio Marina añade a lo anterior un papel decisivo a "una hábil gestión de las restricciones" (Marina, 1993), que en buena medida suelen surgir como consecuencia de la falta de concordancia entre las metas ambiciosas y las propias limitaciones.

En segundo lugar, cabe señalar la enorme dificultad que hay en recorrer el trecho entre el conocimiento de lo verdadero y la limitación del lenguaje para expresarlo. No podemos estar más de acuerdo con el poeta "las palabras acuden a los labios, pero cautelosas, dubitativas, no vaya a ser que estorben a la verdad" (Rumi, 2003). No es ajena la cartografía a este problema, más aun cuando en la actualidad se ha vuelto "fácil" producir mapas dado el apoyo tecnológico existente que pudieran ensombrecer lo que realmente interesa, la verdad. No es buena compañera de viaje para el cartógrafo la producción abundante, rápida, cuando no precipitada, de mapas, hasta crear más confusión que claridad.
Otra cuestión importante es el papel que juega la memoria. Esta cualidad, ciertamente denostada por las modernas tendencias de la educación en los ámbitos académicos, resulta clave, sin embargo, en el trabajo del geógrafo que abre los ojos ante el territorio, lo ausculta, busca correlaciones y trata de sintetizar lo esencial del mismo bien sea en una descripción textual, bien en imágenes cartográficas. Para cumplir esa misión debe ir cargado de un bagaje de conocimientos extenso y profundo, guardado en memoria no a modo de repositorio sin más, sino de archivo operativo bien organizado. Aun así, no todo es aprovechable y se requieren criterios claros para escoger aquello que verdaderamente es nuclear a la hora de generar o representar, en nuestro caso, una información territorial; no cabe duda sobre la infinidad de mapas que se pueden elaborar sobre un determinado tema con el que se quiere caracterizar a un territorio o a la población que en él vive; la observación, la consulta de las fuentes, la propia memoria son recursos utilizados a tal fin, pero es la inteligencia la que decide. En un campo muy distinto al cartográfico propiamente dicho recuerdo la contestación que Augusto Monterroso dio a un periodista cuando este se interesó por el origen de los argumentos de sus novelas: "La vida es como un árbol frondoso que con solo ser sacudido deja caer los asuntos a montones; pero uno puede apenas recoger y convertir en arte unos cuantos" (Monterroso, 1998, citado por An van Hecke, 2009).

El mapa, a mi modo de ver, nunca dejará de ser un producto artesano. Debe ser sometido a correcciones continuas para ajustar bien el mensaje que desea transmitir; esta labor, ingrata para el responsable científico y no pocas veces latosa para el operador cartográfico, sin embargo, no puede soslayarse. "corrijo mucho lo que escribo -decía Caballero Bonald-. Quiero que el texto resulte esmerado, pulcro, rico y con matices" (Salinas, 2015). ¿Quién no desea que sus mapas no tengan estos calificativos?

FIGURA 5

EL CREADOR CARTOGRÁFICO

\section{CUALIDADES DEL CREADOR CARTOGRÁFICO}

- Salud y buen humor

- Sabia gestión de las restricciones

- Dominio del lenguaje visual

- Hábil explotación de la memoria

- Esmero en la redacción cartográfica 


\subsubsection{El proceso creador de Ósip Mandelshtam: ¿al- guna lejana coincidencia?}

No cabe duda que la creación poética poco o nada tiene que ver con el oficio de hacer mapas. No obstante, quiero traer aquí el pasaje en el que Nadiezhna Mandelshtam habla sobre el modo de proceder tanto de su marido Ósip como de Ajmátova a la hora de componer poemas. Muestra un verdadero itinerario que he descrito ante mis alumnos con el fin de hacer una reflexión conjunta y poder sonsacar un aprendizaje provechoso para nuestro quehacer. Una lección magnífica que reproduzco a continuación y comento atrevidamente con el ánimo de señalar algún paralelismo, lejano bien entendido, en el que el cartógrafo puede sentirse identificado.

"Cuentan muchos poetas que la poesía nace del siguiente modo -eso lo dice tanto Ajmátova en el «Poema sin héroe», como Mandelshtam-: Suena en sus oídos una frase musical insistente, al principio inconcreta y luego precisa, pero todavía sin palabras..

En algún instante, a través de la frase musical, brotan de pronto las palabras y comienzan entonces a moverse los labios. Supongo que entre el trabajo del compositor y el del poeta hay algo común, y la aparición de las palabras constituye el momento crítico que separa esas dos formas de creación...

Todo el proceso de la composición consiste en captar con suma atención y dar a conocer lo ya existente -la unidad armónica y racional que ellos captan no se sabe de dónde-y que van plasmando poco a poco en palabras.

La última etapa del trabajo es la expurgación de las palabras casuales en la poesía, que no figuran en el armónico todo que existe antes de ser plasmado. Estas palabras casuales se introducen por la prisa de tapar un hueco cuando surge el todo. Quedan atascadas y su eliminación supone también una difícil labor. En la última etapa se produce el proceso doloroso de escucharse a sí mismo en busca de aquella objetiva y absolutamente exacta unidad que se llama poema...

Observé en su labor poética dos "suspiros de liberación" y no uno. El primero cuando aparecen en la estrofa o la línea las primeras palabras y otro cuando la palabra exacta expulsa los vocablos casuales, intrusos. Entonces el poema se desprende de su creador, deja de zumbar en su oído y atormentarle. El poseso se siente liberado...

Si el poema no se desprende, decía Mandelshtam, significa que algo en él falla o que "tiene aún algo oculto", es decir, que hay un brote fértil del que pretende salir un nuevo germen; dicho de otro modo: el trabajo no está terminado.
Cuando la voz interna se acallaba, ardía en deseos de leer a alguien sus nuevas poesías". (Mandelshtam, 2012)

Resulta sobrecogedor leer estas líneas que acabo de entresacar de las memorias de Nadiezhna Mandelshtam, a sabiendas de que Ósip Mandelshtam fue procesado y padeció sucesivos destierros hasta morir en la Siberia Oriental por haber compuesto un poema en el que aludía al "montañés del Kremlin", a la sazón J. Stalin.

Se nos dice, en primer lugar, que el poeta percibe algo inconcreto que, después adquiere perfiles precisos, aunque sin estar sustentado por las palabras. ¿Acaso, no hay un cierto parangón en el proceder nuestro? Detectamos un interés por un territorio y sus habitantes, nos movilizamos para estudiarlo y darlo a conocer, aunque no poseemos todavía los recursos expresivos que hagan posible el cumplimiento de esto último; más la inquietud no nos dejará tranquilos hasta que nos pongamos manos a la obra.

Es una fuerza imparable la que nos empuja. Hemos "visto" el mapa o conjunto de mapas que van a componer el argumento informativo. La intuición, bien asentada en conocimientos previos y una experiencia suficiente, se convierte en acicate que no nos deja descansar. Puede que hasta deseemos deshacernos de ese móvil que llega a agobiarnos; algo parecido a lo que vivió Ajmátova cuando se puso a lavar la ropa para deshacerse del "Poema sin héroe" cuando le "llegó", pero no consiguió nada. No me parece arriesgado concluir que esta fuerza de la que hablamos está presente en nuestros proyectos cartográficos y es el primer motor que pone en marcha la compleja maquinaria de la producción cartográfica y, en definitiva, la creación de los mapas.

En segundo lugar, desencadenado el proceso, aparecen los primeros mapas. Son aquellas palabras a las que, en su caso, se refiere el poeta. Esos primeros mapas son titubeantes, les suele faltar "carne y hueso"; es decir, una base bien conformada en la que la carga informativa sea equilibrada visualmente y adecuada por su contenido y una expresión temática bien pulida, específica y con cierto valor estético. Son aproximaciones y ensayos hasta encontrar la precisión y el buen gusto exigibles.

Es muy importante lo que el poeta añade a continuación: todo proceso de composición consiste en dar a conocer lo ya existente, eso que él llama "unidad armónica y racional". En efecto, el mapa, como ya se ha dicho, nunca sustituirá a la propia realidad geográfica, tan solo busca aproximarse a ella lo más posible 
y recrearla en una imagen con el fin de hacer más fácil la inteligencia de aquella. Por lo tanto, la nueva creación cartográfica no aporta nada nuevo; es un medio, hecho de lenguaje visual, que transmite algo de lo "ya existente" fuera de él. Lo puede hacer parcialmente mediante los procesos analíticos y de modo más global con la ayuda de metodologías sintéticas.

En un atlas temático o geográfico la proliferación de mapas en la fase de producción cartográfica suele ser muy acusada. Son tantas las posibilidades técnicas de elaborarlos y tan abundante la información científica de partida, bien sea estadística, cartográfica o analógica, que lo normal es acumular un número de mapas muy superior al que en realidad se necesita. El poeta habla de "expurgación de las palabras casuales" cuando "estas se introducen por la prisa en tapar un hueco" en la composición. Esta labor difícil lo es también para el responsable de la realización de un atlas. Este no es la suma de mapas sin más; no es una colección de mapas unidos unos a otros sin relación orgánica, como hemos dicho al principio. Se necesita "expurgar", quitar lo que sobra, pues puede oscurecer lo esencial. Las razones pueden ser varias: una deficiente composición por el desacierto en la simbología; una mala visualización de aquello que realmente se quiso representar debido a un tratamiento inadecuado de la información; una falta de coherencia con el argumento expositivo del atlas; o sencillamente una redundancia de algo ya dicho. Quitar lo que sobra es añadir claridad al atlas.

La última etapa la describe Mandelshtam como "el proceso doloroso de escucharse a sí mismo en busca de aquella objetiva y absolutamente exacta unidad que se llama poema". Nada menos que nos sitúa ante nuestro hipotético atlas para que discernamos si posee unidad y objetividad; estas son dos condiciones que lo pueden definir como excelente o no. Participo del calificativo de "proceso doloroso" pues se trata de evaluar la concordancia o acuerdo entre aquella intuición fundada que nos motivó a desplegar todos nuestros esfuerzos y el resultado obtenido; también debe contemplarse si ese nuevo organismo posee el equilibrio necesario, la flexibilidad óptima y el atractivo indispensable; al mismo tiempo, la realidad geográfica objeto de estudio no debe quedar traicionada, sino más bien hasta ennoblecida, dejando "una puerta abierta para que el espectador capte las cosas a su manera" como señaló A. Tapies en relación a sus creaciones (Salinas, 2015).

En un postrer apunte refiere Mandelshtam que el poema se desprende del creador y este se siente libe- rado. También en esto nuestro trabajo tiene un lejano parecido. El atlas es ya un ente autónomo; ya no nos necesita, ni nos pertenece. Ha iniciado su vida propia y eleva su voz para que se le escuche; adquiere un protagonismo bien notado que los usuarios saben acoger. Caso de no ocurrir ese acto de independencia del poema, insiste Mandelshtam, es que el trabajo no está terminado: "algo falla en el o tiene algo oculto". Dramática situación sería para un atlas no alcanzar la condición de adulto y necesitar permanente tutela de sus ejecutores.

Esta glosa que acabamos de hace tan solo quiere mostrar lo que, a mi parecer, son las claves que pueden, metafóricamente, aproximar nuestro trabajo al de los creadores artísticos. No sé si es muy petulante tal metáfora; me parece adecuado hacerlo sobre todo para incentivar la reflexión a los jóvenes que, dominadores de las nuevas tecnologías, pudieran acaso pensar que los mapas y los atlas son tan solo un producto exclusivamente técnico.

FIGURA 6

LA CREACIÓN CARTOGRÁFICA

\section{PROCESO DE CREACIÓN CARTOGRÁFICA}

- Del interés a la inquietud

- Intuición visualizada

- Primeros mapas inmaduros

- Lo nuevo y lo real en el mapa

- Expurgación cartográfica

- Coherencia, equilibrio, flexibilidad y atractivo

- Autonomía del mapa

\section{LA EXPRESIÓN CARTOGRÁFICA EN EL SIGLO XXI: VALORES FUNDAMENTALES}

Hace ahora algo más de treinta años preparaba Italo Calvino unas conferencias para ser impartidas en la Universidad de Harvard durante el curso académico 1985-86. Una semana antes de emprender su viaje, murió. Su hermana, Esther Calvino, publicó los textos de las cinco primeras, bajo el título "Seis propuestas para el próximo milenio", en una edición de Siruela en castellano en 1989. Calvino dibuja un panorama de la creación literaria sostenido, según él, por "algunos valores, cualidades y especificidades que me son particularmente caros, tratando de situarlos en la perspectiva del nuevo milenio". Esos valores son los que, a mi parecer, pueden servirnos de guía también a quienes nos preocupamos por dar a conocer el territorio y sus gen- 
tes a través de los mapas. Glosaré brevemente algunas ideas, entresacadas de la publicación citada, que me han parecido más cercanas a nuestro quehacer.

El primer valor que considera Italo Calvino es la levedad. Sostiene que el mundo se nos presenta un tanto opaco, pesado y ciertamente compacto; sin embargo, la ciencia ha demostrado que son entidades sutilísimas quienes lo sostienen y precisamente su conocimiento es el camino seguro para poder disolver esa compacidad. Esta dualidad entre pesadez y levedad la notamos también a la hora de representar el territorio a través de los mapas; necesitamos ir al trazo fino, buscar las características singulares que pueden ayudar a definir un territorio "compacto", a sabiendas que hacemos un artificio. Esa búsqueda y elección de lo "sutil" es costosa y no siempre acierta a romper la opacidad y, por tanto, la cabal comprensión, por ejemplo, de un paisaje.

Unido a lo anterior, Calvino abunda en que los procesos mediante los que se han creado las cosas llevan el sello de la precariedad: "poco faltó para que el hombre no fuera hombre, y la vida la vida, y el mundo un mundo". Esta idea nos lleva a pensar en la dificultad que tiene el geógrafo en ofrecer un abanico completo de "detalles cartográficos" con los que poder acercarse a una comprensión y explicación del territorio, aunque bien sabemos que la "precariedad" está en la raíz misma de la vida de la comunidad humana y el entorno natural e histórico en el que habita. La transposición del "peso y espesor" del objeto de estudio al lenguaje no siempre es fácil, como se ha dicho reiteradamente en líneas anteriores. En un atlas temático, podría quedar nuestro argumento cartográfico a modo de voces que flotan sobre la realidad sin una verdadera trabazón con esta; esta sería la peor de las situaciones para el producto citado. Por tanto, los mapas sin perder levedad deben tener el peso debido; en suma, deben "asociarse con la precisión y la determinación, no con la vaguedad y el abandonarse al azar". El propio Calvino cita a P. Valery para sentenciar la idea: "Ser ligero como un pájaro y no como una pluma".

Algunas veces hemos utilizado en este trabajo la expresión "discurso cartográfico" como indicativo de la exposición secuenciada de mapas que sostienen un argumento de contenidos en un atlas temático. Hoy, puede que más que nunca, se busca la comunicación inmediata; la rapidez se ha convertido en un valor. El discurso cartográfico es, de hecho, un instrumento potente para hacer posible la rapidez en la adquisición por parte del usuario de información localizada; y lo es por dos motivos que subyacen al conjunto orgánico de los mapas: el razonamiento implícito que hay en el mismo y la velocidad que se le puede dar al proceso de aprehensión. Discurrir es, al mismo tiempo, razonar y correr.

La construcción del discurso cartográfico debe, sin embargo, ser paciente y requerir la dilación necesaria para su maduración. "Búsqueda de la palabra exacta, frase en la que cada palabra es insustituible,... búsqueda de una expresión necesaria, única, densa, concisa y memorable": ¿Se puede tener mejor programa para quien elabora mapas que esta declaración que I. Calvino aplicaba a la composición literaria?

La tercera de las conferencias que I. Calvino preparó estuvo dedicada a la exactitud. Valor que el autor pone de relieve para el nuevo milenio. Tres son las condiciones que debe reunir una creación literaria para participar de este valor: un diseño de la obra bien definido y bien calculado; la evocación de imágenes nítidas, incisivas y memorables; el lenguaje más preciso posible como léxico y como expresión de los matices del pensamiento y la imaginación. Esta definición conviene perfectamente a nuestro oficio.

La precisión y el rigor, una vez más, se erigen como guías insustituibles. Sin embargo, señala I. Calvino, "el lenguaje es usado cada vez más de forma aproximativa, casual, negligente"; llega a hablar de "epidemia pestilencial que azota a la humanidad" cuando las imágenes se multiplican sin sentido y no tienen la necesidad interna exigible. Buena lección para nosotros que trabajamos con imágenes cartográficas y en manera alguna podemos tratar de modo negligente una herramienta tan poderosa.

La idea de comparar el proceso de creación de una película a la construcción del discurso cartográfico la he utilizado algunas veces ante mis alumnos. La expresión "la película del atlas" me ha servido cuando he intentado mostrar ante ellos que un atlas esconde siempre un relato, una historia, hecha de mapas en la que la comunicación del conocimiento científico se hace compatible con el agrado de ver una composición sugerente, atractiva y de fácil memorización. Dar visibilidad al territorio mediante los mapas temáticos es el objetivo del proceso de elaboración cartográfica y ese, precisamente, fue el cuarto valor que I. Calvino propuso: "la visibilidad hay que salvarla. Eso evitaría el peligro de perder una facultad humana fundamental: pensar en imágenes".

Por último, la multiplicidad, considerada por Calvino como valor, viene a corroborar que la realidad 
geográfica se sostiene sobre una madeja de relaciones no siempre fácil de desvelar. Así vieron el mundo muchos creadores literarios: "cada objeto está visto como una red de relaciones que el escritor no puede dejar de seguir, multiplicando los detalles de tal manera que sus descripciones y divagaciones son infinitas". Nuestros atlas temáticos o geográficos son viva expresión de esa multiplicidad que no pretende sino trazar un camino óptimo para la comprensión de la realidad geográfica. No obstante, un Atlas no es una enciclopedia cuyo objetivo, como es bien sabido, es encerrar todo el saber en sus páginas; mas bien es un horizonte abierto que se actualiza permanentemente gracias a las nuevas tecnologías de la comunicación, da cabida a nuevas hipótesis de trabajo y acoge el descubrimiento de nuevas relaciones territoriales y humanas que contribuyen a hacer más comprensible el territorio y la comunidad humana que lo habita.

Estos fueron los cinco valores que Italo Calvino propuso para el nuevo milenio. Nosotros los hacemos nuestros y la cartografía temática debe tenerlos, a nuestro parecer, como frontispicio que guíe el buen hacer de sus cultivadores.

FIGURA 7

VALORES FUNDAMENTALES DE LA CREACIÓN CARTOGRÁFICA A COMIENZOS DEL III MILENIO

\section{VALORES ACTUALES DE LA CREACIÓN CARTOGRÁFICA}

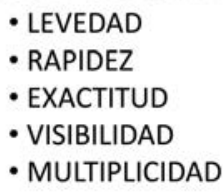

- EXACTITUD

- VISIBILIDAD

- MULTIPLICIDAD

\section{CONCLUSIÓN}

Es tiempo de concluir y no es fácil. La reflexión precedente debería, más bien, quedar abierta. Como es bien sabido, no son pocos los escritores que han dejado abiertos sus relatos, interminablemente extensos como los de Marcel Proust (1997) o Robert Musil (2002). Sus descripciones minuciosas entrelazan matices, multiplican las relaciones y se niegan a concluir. El primero de los autores citados, en su obra "Sobre la Lectura", indica que un libro es preferible que muestre incitaciones en vez de conclusiones. Siempre es más lo que queda por decir. Por eso, hubiera preferido titular este colofón "Incitaciones", pero mi atrevimiento no llega a tanto.
En un discurso cartográfico me atrevo a decir que pasa lo mismo. Lo inasible del territorio hace, por ejemplo, que nuestros atlas temáticos de alguna manera sean también interminables. Un mapa nos lleva a otro; un mapa nos descubre que hay nuevos matices por desvelar. Los mapas en su conjunto crean una madeja de correlaciones compleja, copiosa y en permanente crecimiento.

No obstante, sí quiero dejar constancia, al menos de unas pocas ideas. La primera alude a no descuidar nunca la reflexión sobre el propio quehacer. La elaboración de mapas y atlas temáticos exige una atención cuidadosa, no solo por la atención que requieren las técnicas y herramientas de producción cartográfica, la preparación de la información territorial con vistas a su representación visual y el manejo de un lenguaje de enorme potencialidad, sino, sobre todo, porque la prisa y el activismo pueden hacer que desmerezca una sosegada reflexión. Los mapas deben seguir siendo un producto artesano que ha sabido incorporar lo nuevo en el sustrato de una tradición arraigada y fecunda.

En segundo lugar, no parece exagerado decir que el proceso cartográfico tiene también algún parentesco con otros procesos más claramente catalogados como "creadores". Todo parece indicar que nuestro oficio, a su escala, participa de aquel marco común en que escritores y artistas despliegan su genialidad. Animo, por ello, a que los jóvenes que se incorporan al trabajo de "hacer mapas y atlas temáticos" no descuiden una formación amplia que asegure unos cimientos culturales profundos y les permita sentir como propios los desafíos actuales en orden a la expresión gráfica, artística y literaria.

Por último, lo antedicho estimo es condición necesaria para desvelar con acierto esos valores que, en el fondo, es lo que deseamos transmitir: no basta que un mapa sea correcto técnicamente, sí es ineludible que sea verdadero; no solo es imprescindible que un mapa ofrezca una información científica inteligible, sino que es necesario, al mismo tiempo, que sea lo suficientemente atractivo; no basta que un mapa sea "bueno" por su veracidad científica, corrección sintáctica, claridad perceptiva y valor estético, sino que es preciso que influya decisivamente en la formación cabal del posible usuario y contribuya directa o indirectamente en la mejor gestión de un territorio y el bienestar y el desarrollo de la sociedad humana que lo habita. 


\section{BIBLIOGRAFÍA}

Calvino, I. (1989). Seis propuestas para el próximo milenio. Madrid:Ediciones Siruela, 144 p.

Delclaux, F. (1996). El silencio creador (5a ed.). Madrid: Rialp, 208 p.

Hecke, A. van (2009). El árbol de Monterroso: reflexiones sobre el difícil balanceo entre imaginación y realidad. En E. Houvenaghel e I. Logie (eds.), Alianzas entre historia y ficción. Homenaje a Patrick CoIlard (pp. 409-418). Genève: Droz.

Mandelshtam, N. (2012). Contra toda esperanza. Memorias. Barcelona: Acantilado, 643 p.

Marina, J.A. (1993). Teoría de la inteligencia creadora. Barcelona: Anagrama, 382 p.

Musil, R. (2002). El hombre sin atributos. Seix Barral, Biblioteca Formentor, 2 vols. de 684 y 872 p.
Perutz, L. (2016). De noche, bajo el puente de piedra. Barcelona: Libros del Asteroide, 283 p.

Proust, M. (1997). Sobre la lectura. Valencia: Pre-Textos, $68 \mathrm{p}$.

Rilke, R.M. (2004). Cartas a Rodin. Madrid: Editorial Síntesis, $175 \mathrm{p}$.

Rumi, Yalal ud-Din (2003). Rubayat. Ediciones del oriente y del mediterráneo / Ediciones UNESCO, 197 p.

Salinas, F. (2015). Ya nadie cree en las musas. Lecturas Sumergidas, 29. Recuperado de https://lecturassumergidas.com/2015/12/17/ya-nadie-cree-en-lasmusas/

Tsvietáieva, M. (2015). Diarios de la Revolución de 1917. Barcelona: Ed. Acantilado, 223 p. 